\title{
CLASSICA: O INÍCIO
}

CLASSICA: THE BEGINNING

Filomena Y. Hirata*

Recebido em: 03/08/2019

Aprovado em: 23/08/2019

$\mathrm{F}$ Tundada em 1985, durante a $37^{a}$ reunião da Sociedade Brasileira para o Progresso da Ciência, em Belo Horizonte, a Sociedade Brasileira de Estudos Clássicos por meio de seus membros fundadores, sobretudo de sua diretoria, começou imediatamente a árdua tarefa de organização e funcionamento da Sociedade. Era preciso definir a competência do Conselho Consultivo-Deliberativo e do Conselho Fiscal bem como criar as secretarias regionais que deveriam dar conta deste imenso Brasil geograficamente dividido, se não totalmente, pelo menos, das regiões onde houvesse minimamente estudos clássicos. Era fundamental que professores das universidades ou faculdades públicas e privadas ligados aos estudos clássicos soubessem que a SBEC tinha sido fundada e se associassem a ela. A pretensão era elevada e muitos professores mais antigos, que tinham uma mínima experiência com associações, eram céticos em relação à sociedade que se iniciava. Deixando de lado essa parte que diz respeito à burocracia e ordenação da aglomeração humana, um dos objetivos mais importantes da nova sociedade era a criação de uma revista que tornasse visível a todos a produção científica brasileira. Haiganuch Sarian, presidente da SBEC, e Jacyntho Lins Brandão, secretário geral, escolheram a primeira comissão editorial da revista, composta pelos professores José Cavalcante de Souza, Ulpiano Bezerra de Menezes, Norberto Guarinello e Filomena Hirata. Todos da Universidade de São Paulo, o que facilitaria os encontros e as reuniões, que foram muitas e, frequentemente, supervisionadas pela presidente e pelo secretário. É bom esclarecer que Jacyntho, na época, vinha muito à USP, onde fazia o doutoramento. Que as reuniões fossem muitas compreende-se: a comissão editorial tratou de tudo que dizia respeito à revista, do nome, do conteúdo e da forma. O objetivo era sempre chegar a um consenso.
* Professora de língua e literatura grega, Faculdade de Filosofia, Letras e Ciência Humanas, Universidade de São Paulo.

fhirata@usp.br 
De início, definimos o nome CLASSICA, uma só palavra que conseguia comportar diversos setores culturais das atividades humanas como, por exemplo, a literatura, a filosofia, a história, a arqueologia, a filologia, com razoável amplitude geográfica, isto é, que poderia não se restringir apenas a Grécia e Roma, mas também abranger outras civilizações mais antigas. O conteúdo seguia, mais ou menos, o modelo das revistas tradicionais estrangeiras, ou seja, primeiro, viria um conjunto de artigos e, depois, um conjunto menor de resenhas bibliográficas. Os artigos poderiam ser o resultado de alguma pesquisa relevante realizada pelo autor, assim como traduções anotadas de documentos, ensaios bibliográficos, enquanto as resenhas críticas deveriam se concentrar em obras importantes para os estudos clássicos e com datação recente. Salvo casos bem justificados, como poderia ocorrer com as traduções, os trabalhos deveriam ser inéditos. E ainda, autores estrangeiros também poderiam colaborar com seus trabalhos. Por fim, preocupada com o nível intelectual da revista, a comissão decidiu que todos os trabalhos encaminhados passariam pela apreciação de um assessor especialista da área, convocado para esse fim. Tentei resumir aqui alguns itens que estão na "apresentação", redigida pela comissão editorial e publicada no primeiro volume da CLASSICA.

Voltando ao passado, mais de trinta anos atrás, lembro-me, ainda, do clima pouco confortável que se instaurou entre os associados, os autores em potencial, ao tomarem ciência das normas. Afinal, o Brasil não era a Europa! A comissão estava sendo muito exigente! E não era difícil entender a situação. Professores que nunca antes tinham participado de uma sociedade como a Sociedade Brasileira de Estudos Clássicos, que nunca tinham visto uma revista como CLASSICA, só poderiam ter esse tipo de reação. Na verdade, estávamos saindo do limbo! Um ano antes da fundação da SBEC, Jacyntho Lins Brandão organizou o Primeiro Congresso Nacional de Estudos Clássicos na UFMG, Belo Horizonte, em 1984. Vários professores de vários estados do Brasil compareceram e se surpreenderam ao verificar que ninguém sabia o que os outros colegas faziam em outros lugares. Era importante fundar um centro de comunicação entre as diversas universidades. Foi o embrião. Muitos professores acolheram a ideia. De qualquer forma, apenas para completar o que acaba de ser dito, cabe relatar que esta experiência não era totalmente nova. Um exemplo: bem antes da SBEC, houve, na Universidade de São Paulo, uma Associação de Estudos Clássicos do Brasil, fundada por professores renomados, dentre os quais o prof. Robert Henri Aubreton, seu primeiro presidente. Esta associação, que durou de 1984 a 1990, publicava anualmente o Boletim de Estudos Clássicos, que reunia um conjunto de informações administrativas, pelas quais era possível acompanhar o funcionamento e a história da associação. Só no final vinham alguns artigos de docentes. O Boletim tinha um traço marcante: um particular interesse pelo que ocorria na época. Assim, ele informava a luta persistente dos professores pela criação de cursos de grego no secundário e, mais tarde, pela manutenção do "ensino clássico", ou seja, do grego e, sobretudo, do latim nos colégios. Mostrava também a resistência dos professores à eliminação do exame de latim no vestibular de Direito. O Boletim informava também que Associação era filiada à FIEC, desde o seu início. Como se pode ver, os tempos eram outros e as preocupações também.

CLASSICA nasceu com um caráter desafiador, porque o essencial é o conteúdo que ela veicula, ou seja, a produção cultural dos docentes e, tendo a atribuição de ser o 
órgão oficial da SBEC, tinha que difundir essa produção de qualidade, visando a colaborar para o desenvolvimento dos estudos clássicos no Brasil. Assim sendo, em vista das metas propostas, é compreensível que os artigos para publicação, no início, tenham demorado um pouco a aparecer, bem como a revista, mas esta por causa das dificuldades do financiamento. CLASSICA, enfim, foi publicada em 1988, cumprindo o quanto possível o que fora anunciado e com a participação razoável de artigos de autores estrangeiros. O quanto possível porque fica a pretensão de que ela sempre poderá ser melhor, uma vez que faz parte de sua natureza a busca de constante aprimoramento crítico.

Segue-se o sumário da revista, tendo sido acrescentado o nome das instituições em que trabalhavam os autores na época.

\section{Artigos:}

Ciro F. S. Cardoso: Economia e sociedades antigas. Conceitos e debates (UFF)

Donaldo Schüler: A poesia no sistema de Heráclito (UFRS)

Jacyntho J. L. Brandão: O poeta na casa do rei (UFMG)

João Pedro Mendes: Linguagem: natureza ou convenção? (UnB)

Maria da Glória Novak: Epicuro e a natureza da alma (USP)

Nicolaos Yalouris: La contribution des jeux au dévéloppement des lettres et des arts en Grèce (Musée National d'Athènes)

Lilly Gali-Kahil: A iconografia clássica e sua inovação (Université de Fribourg)

René Ginouvès: Perspectives actuelles de l'archéologie classique (Université de Paris-Nanterre)

Zélia de Almeida Cardoso: O mundo das sombras na poesia latina (USP)

Ulpiano T. Bezerra de Menezes: A fundação de cidades e o imaginário urbano: releitura de Tito Lívio (USP)

\section{RESENHAS CRÍticas:}

Haiganuch Sarian: Lexicon Iconographicum Mythologiae Classicae, II (USP)

Christian Jacob: A. Snodgrass, La Grèce Archaique. Le temps des apprentissages (CNRS)

Pedro Paulo A. Funari: J. Remezal Rodrígues, La annonna militaris y la exportación de aceite bético a Germania (UNESP-Assis).

Como mostra o sumário, os textos publicados pertencem todos a professores reconhecidos no meio universitário e a professores estrangeiros. Estes primeiros anos de vida da SBEC ao lado da publicação de sua revista representam um momento único para todos os professores da área de estudos clássicos. Até aí talvez se pudesse dizer que a revista era um espelho da Sociedade. No entanto, o tempo passa e as coisas mudam, não necessariamente para melhor ou pior, apenas mudam. Se tomarmos CLASSICA 2, a título de comparação e exemplo, em relação a CLASSICA 1, vamos perceber que alguma diferença já aparece. 
De início, percebe-se que um número bem maior de professores atendeu à solicitação de publicação, assim como professores cursando mestrado e doutorado. Ao mesmo tempo, a comissão também abriu o leque de aceitação, tornando-o mais flexível. Assim, ao lado de um artigo como o de Anna Lia de Almeida Prado, professora de grego, sobre "O lógos de Tucídides sobre a guerra", CLASSICA 2 publicou, da igualmente professora de grego Ísis Borges da Fonseca, "Ulisses na Odisséia de Kazantzákis". Continuando a tendência de abertura, CLASSICA 3 publicou da professora Ísis Borges da Fonseca "O gênero deliberativo na oratória grega: a Terceira Filípica de Demóstenes e a Retórica de Aristóteles", ao lado de "La religion de l'Antique, de Ciceron à Chateaubriand: le signe et le sens" de Suzanne Gély. Ainda mais, CLASSICA 3 muda a disposição interna dos artigos, abrindo duas seções especiais na revista, uma intitulada "Classicismo e Modernidade", em que o texto citado se enquadra, e outra intitulada "Crônica", onde se relatavam notícias sobre eventos, colóquios que ocorriam em outros lugares. Não se trata de fazer um julgamento de valor sobre os novos rumos da revista. Trata-se apenas de aceitar o que se impõe, o que é reflexo da formação individual dos docentes, da diversidade cultural do país e até mesmo das teorias literárias que vingam em nosso meio cultural, em determinados tempos. Se, aberto o leque, a recepção aumenta, é preciso ao menos considerar isso, ainda que seja um desvio da meta inicial.

É muito provável que as mudanças que ocorreram em CLASSICA sejam uma consequência do que aconteceu na assembleia geral da SBEC em Curitiba, em 1986. Após uma grande discussão entre os professores presentes sobre os rumos da SBEC, discussão democrática sem dúvida, chegou-se a um consenso no sentido de que a sobrevivência da Sociedade era fundamental e isso implicava o respeito às diferenças e à individualidade de todos os seus membros e a aceitação de um sentido mais amplo da palavra "clássica".

Por fim, é preciso falar da capa da revista. Em preto e sépia, cores fortes da cerâmica grega, a capa se sobressai. Foi Jacyntho quem a encomendou do artista mineiro Paulo Roberto Coelho. Sobre a cor sépia, estende-se a palavra CLASSICA em preto, com uma divisão de sílabas pouco convencional. No entanto, é isso que chama a atenção logo de início. Lembrome de que um dia, na Faculdade de Letras, ao ver a revista em minhas mãos, a professora de língua e filologia portuguesa, Nilce Sant'Anna Martins, fez um elogio à beleza da revista, mas confessou que não conseguia deixar de se sentir incomodada com a divisão da palavra CLA SSI CA. Lembro-me vagamente de ter respondido a ela que ali residia a essência da revista: um sinal de modernidade que resgata o passado. Depois de alguns anos, é claro, a capa também sofreu suas mudanças.

Concluindo, resumi aqui alguns fatos que marcaram o início da SBEC e da CLASSICA, a maneira pela qual ambas foram trilhando seus caminhos de forma equilibrada e dinâmica. À SBEC cabe o mérito de ter cumprido rigorosamente a tarefa de organizar seus congressos, no início, a cada ano e, depois, a cada dois anos, e de publicar a revista anualmente, e depois semestralmente. E mais, não fosse a certeza de que cada membro associado guardaria sempre na memória a importância dos estudos clássicos na cultura brasileira, a SBEC não estaria completando 34 anos e CLASSICA 31 anos, em 2019. 